\title{
CONTRIBUIÇÕES FEMINISTAS PARA O PENSAMENTO DECOLONIAL: REFLEXÕES ACERCA DAS FILOSOFIAS DE ENRIQUE DUSSEL E ANÍBAL QUIJANO
}

\author{
Amanda Soares de Melo ${ }^{1}$
}

\begin{abstract}
Resumo
O presente trabalho consiste em uma análise das teorias do pensamento decolonial latinoamericano, mais especificamente de Quijano e Dussel, a partir de uma perspectiva feminista que abrange os problemas de gênero na construção da colonialidade e da decolonialidade. As filosofias de Dussel e Quijano, assim como de outros autores decoloniais, trouxeram excelentes ferramentas teóricas para pensar a condição de subordinados no mundo. No entanto, submetidos ao escrutínio feminista, eles ainda revelam traços de um pensamento masculinista, que é incapaz de cobrir adequadamente a experiência das mulheres. Algumas reflexões do pensamento feminista latino-americano de Breny Mendonza e Maria Lugones sobre essas teorias podem melhorar a compreensão das relações de gênero no contexto colonial/decolonial.
\end{abstract}

Palavras-chave: feminismo decolonial, pós-colonialismo, estudos subalternos, filosofia da libertação.

\begin{abstract}
The present work consists of an analysis of Latin American decolonial thought theories, more specifically of Quijano and Dussel, from a feminist perspective that covers the problems of gender in the construction of coloniality and decoloniality. The philosophies of Dussel and Quijano, as well as of other decolonial authors, have brought excellent theoretical tools to think of the condition of subordinates in the world. However, undergoing feminist scrutiny, they still reveal traces of a masculinist thinking, which is unable to adequately cover the experience of women. Some reflections of Breny Mendonza and Maria Lugones' Latin American feminist thinking on these theories may enhance the understanding of gender relations in the colonial / decolonial context.
\end{abstract}

Keywords: decolonial feminism, post colonialism, subaltern studies, philosophy of liberation.

\footnotetext{
${ }^{1}$ Universidade Federal do ABC. E-mail: 010amanda@gmail.com 


\section{Pensamento decolonial e pós-colonial: aproximações e diferenças}

Um dos graves efeitos do imperialismo e do colonialismo nas regiões sul-americanas foi o epistemicídio decorrente da imposição de valores eurocêntricos, incluindo o patriarcalismo, sobre os povos nativos e escravizados. O imperialismo exportou para o mundo toda uma lógica de pensamento que passou a ser dominante, cujos traços são amplamente reconhecidos pelas categorias universais, hegemônicas, binárias, dicotômicas e hierárquicas de gênero, orientação sexual, raça/etnia, classe social e localização (centro-periferia). A centralidade na razão europeia dificultou, por muito tempo, um pensamento reflexivo sobre a condição subalterna dos povos nativos desde os intelectuais da região. No artigo "A filosofia da libertação frente aos estudos pós-coloniais, subalternos e a pós-modernidade”, Dussel traça um panorama do pensamento pós-colonial e suas interfaces com o pensamento latinoamericano, que traz para a filosofia uma nova racionalidade política, crítica do universalismo, seja ele dogmático ou fundacional, partindo de posições consideradas não tradicionais.

Pode-se dizer, seguindo Dussel, que o pensamento latino-americano exerce certo pioneirismo na problematização da herança europeia. Em meados da década de 1940, na América Latina, temos um notável interesse por parte de filósofos como Augusto Salazar Bondy, Leopoldo Zea, Artur Ardão ou Francisco Romero, de continuar a reflexão acerca do pensamento latino americano iniciada no século XIX por Juan Batista Alberdi. Tratava-se, entre outras coisas, de se pensar a emancipação da nuestra américa frente ao pensamento herdado da colonização, seus limites e possibilidades. No ambiente europeu, a autocrítica só iria se fundar, a partir dos anos setenta, com Michel Foucault sendo protagonista dessa reflexão. Foucault se opusera às posições metafísicas e a-históricas do marxismo teleológico, isto é, aquele que invoca o proletariado como um “sujeito messiânico”, que tece o curso necessário e progressivo da história, que afirma o poder macroestrutural como o único existente. Além dele, temos Deleuze, Derrida e Lyotard contra a razão moderna, pensada sob a categoria de totalidade de Emmanuel Lévinas. O livro “A condição pós moderna” (1979) de Lyotard, torna-se um manifesto desse movimento, que não se limita à crítica do marxismo, mas extrapola para a crítica da vertente universalista de terror e violência contida na racionalidade moderna. Frente a essa unicidade, eles apelam para a diferença, a multiplicidade, a pluralidade, a fragmentariedade, a desconstrução de todo macro relato (DUSSEL, 2017, p. 3237).

O movimento pós-moderno chega na América Latina no final dos anos de 1980, tomado por intelectuais com o objetivo de se evadir dos dualismos de centro-periferia, atrasoprogresso, tradição-modernidade, dominação-libertação e transitar pela heterogênea, 
fragmentária, diferencial cultura transnacional urbana (DUSSEL, 2017, p. 3236). Um dos representantes dessa corrente é o pensador Santiago Castro-Gómez que tece críticas ao pensamento progressista latino-americano, constituído por Vásquez, Hinkelammert, Guadarrama, Roig, Zea, Salazar Bondy etc. A crítica consiste que em todos esses casos, sob a pretensão de criticar a Modernidade, estes filósofos não conseguem sair da Modernidade pois recuperam conceitos como sujeito, história, dominação, dependência externa, classes sociais oprimidas, massas populares, exterioridade, libertação, esperança, etc. Falar então de macroinstituições como o Estado, a nação, o povo, das narrativas épicas heróicas seria ter perdido o sentido do micro, heterogêneo, plural, híbrido e complexo (DUSSEL, 2017, p. 3237). De forma semelhante, E. Dussel complementa a crítica de Castro-Gómez ao afirmar que Foucault critica certas formas de sujeito, enquanto valoriza outras; critica as formas de se fazer história desde leis a priori, mas revaloriza uma história genética epistemológica. Para ficar mais claro, ele parafraseia Eduardo Mendieta: “a pós-modernidade perpetua a intenção hegemônica da modernidade e da Cristandade ao negar a outros povos a possibilidade de nomear a sua própria história e de articular seu próprio discurso autorreflexivo” (MENDIETA, 1998, p. 159 apud DUSSEL, 2017, p. 3238).

Autores como Foucault, Lacan e Marx, ou Lévinas acabaram por influenciar o desenvolvimento de filosofias pós-coloniais, que surgem da necessidade de uma crítica para além dos pressupostos da modernidade, sendo ela mais radical e politicamente efetiva ao expressar o compromisso político com os “subalternos” da periferia global. É o caso do grupo Subaltern Studies, cujo principal objetivo era “analisar criticamente não só a historiografia colonial da Índia feita por ocidentais europeus, mas também a historiografia eurocêntrica nacionalista indiana” (BALLESTRIN, 2013, p. 92). De forma paralela, esse grupo acabou por reforçar o pós-colonialismo como um movimento epistêmico, intelectual e político.

Na década de 1980, os Subaltern Studies ganharam repercussão internacional. Pouco tempo depois, Spivak publicou um artigo que se tornou um marco do pós-colonialismo: "Pode o subalterno falar?”. Nesse artigo, a autora critica a prática discursiva intelectual de autores como Deleuze e Foucault, incluindo próprios membros do grupo, que pretendem falar em nome do sujeito subalterno, enquanto este, é aquele cuja voz não pode ser ouvida; Para ela "nenhum ato de resistência pode ocorrer em nome do "subalterno"” sem que esse ato seja imbricado no discurso hegemônico” (BALLESTRIN, 2013, p. 93. Nesse caso, o "subalterno” permanece silenciado e aparece como constituição de mais um “outro”, uma classificação essencialista que acaba por não incorporar a noção de différance ou hibridismo. Para a autora, o intelectual pós colonial, ainda que queira, não pode falar pelo "subalterno”. 
Já em 1992, intelectuais latino-americanos e americanistas fundaram o Grupo LatinoAmericano dos Estudos Subalternos, inspirado no grupo asiático. O manifesto inaugural foi traduzido por Santiago Castro-Gómez para o espanhol apenas em 1998, com o nome de “Manifiesto inaugural del Grupo Latinoamericano de Estudios Subalternos”. Esse manifesto inaugural incorporava vários dos temas abordados pelos indianos, a partir dos quais se pretendia avançar para uma reconstrução da história latino-americana das últimas duas décadas (BALLESTRIN, 2013, p. 95). A partir desse manifesto, a América Latina foi a inserida no debate pós-colonial. Contudo, Walter Mignolo, a voz mais crítica e radical do grupo latino americano de estudos subalternos, demonstrou seu descontentamento quanto a essa perspectiva. Ele faz uma crítica a forma como a América Latina importa o debate póscolonial, pensa que os textos dos teóricos indianos não deveriam ser simplesmente assumidos e traduzidos para análise direta da experiência latino-americana. Para ele, a trajetória da América Latina de dominação e resistência estava oculta no debate. A história do continente para o desenvolvimento do capitalismo mundial fora diferenciada, sendo a primeira a sofrer a violência do esquema colonial/imperial moderno. Mignolo afirma que as teorias pós-coloniais têm seu lócus de enunciação nas heranças coloniais do império britânico e que é preciso, por isso, buscar uma categorização crítica do ocidentalismo que tenha seu lócus na América Latina (BALLESTRIN, 2013, p. 95).

Devido às divergências, o grupo teve seu fim em 1998, ano em que ocorreram os primeiros encontros entre os membros que, posteriormente, formariam o Grupo Modernidade/ Colonialidade. Ramón Grosfoguel, ao narrar seu descontentamento com o projeto do Grupo Latino-Americano dos Estudos Subalternos, atribuiu duas razões para sua dissolução: incapacidade do grupo em romper com a episteme, ao seu ver, ainda centrada no Norte e a divergência quanto ao que caracterizava a subalternidade de uma crítica: “a crítica eurocêntrica ao eurocentrismo (pós moderna)” ou “a crítica que parte dos saberes dos povos silencializados (decolonial)” (BALLESTRIN, 2013, p. 96). Assim, para aqueles que tomaram o partido da última fazia-se necessário transcender epistemologicamente, ou seja, descolonizar a epistemologia de seus cânones ocidentais. Entre os membros do novo grupo estavam: Edgardo Lander, Arthuro Escobar, Walter Mignolo, Enrique Dussel, Aníbal Quijano e Fernando Coronil, Immanuell Wallerstein, Santiago Castro-Gómez, Oscar Guardiola, Zulma Palermo e Freya Schiwy. A bem da verdade, desde os anos setenta, muitos dos integrantes do grupo já haviam desenvolvido linhas de pensamento próprias, como é o caso de Dussel e a Filosofia da Libertação e de Quijano e sua Teoria da Dependência. 
No caso da Filosofia da Libertação de Dussel, dá-se o surgimento quase ao mesmo tempo que o grupo "Subaltern Studies”. Sua originalidade reside, entre outras coisas, em mostrar para o mundo que, sob um horizonte da metrópole/colônia, o "excluído" e "vigiado" no manicômio e na prisão panóptica de Foucault, havia sido antecipado em séculos pelo índio excluído vigiado nas “reduções”, povos e doutrinas da América Latina desde o século XVI (DUSSEL, 2017, p. 3242). De forma similar, o negro vigiado na senzala junto à Casa Grande havia surgido em 1520 em Santo Domingo, quando terminou exploração do ouro dos rios e começava a produção de açúcar. Partindo do Outro de Lévinas, que se denomina pelo “distinto” (porque a “diferença” se definia desde a “identidade”) (DUSSEL, 2017, p. 3242), podemos ver o excluído e vigiado de Foucault. A Filosofia da Libertação toma emprestado esse conceito não sem fazer oposição ao próprio Lévinas, que somente pensava no contexto Europeu e sem pensar criticamente a responsabilidade da vulnerabilidade do Outro (DUSSEL, 2017, p. 3242).

Em linhas gerais, para Dussel, o filósofo tem a responsabilidade de lutar pelo Outro; seja a mulher oprimida pelo machismo, as gerações futuras com a Terra destruída, a criança no sistema de educação bancário etc. Assim, se abre a qualquer ser humano que sofre como o Outro, uma sensibilidade ética que saiba indignar-se frente à injustiça sofrida por ele. Para isso, se faz necessário ferramentas teóricas e, isso englobaria o pós-moderno, embora não sejam suficientes para a práxis da libertação (DUSSEL, 2017, p. 3243). Dessa forma, o autor adverte que quaisquer dualismos como centro-periferia, desenvolvido-subdesenvolvido, enquanto superficial ou reduzidamente utilizados, deve ser superado. Porém, superado não quer dizer que se pode “decretar” sua negação (fazendo alusão ao pensamento "pósmoderno”). Supor que não há dominadores nem dominados, nem centro nem periferia, seria cair em um erro grave. As lutas são inúmeras (a da mulher, ecologistas, as raças discriminadas, nações dependentes). O proletariado não é um “sujeito metafísico” eterno, mas pode ser um sujeito coletivo, intersubjetivo, que apareça e possa desaparecer em certas idades históricas. Em sua visão, a Filosofia da Libertação tem recursos teóricos para afrontar os desafios presentes, usando meta-categorias como totalidade e exterioridade como referências abstratas e globais que devem ser medidas pelas microestruturas de poder, no qual ninguém poderia se declarar inocente. Esses ferramentais teóricos devem ser reconstruídos desde a América Latina (DUSSEL, 2017, p. 3247).

Em Teoria da Dependência, de 1989, Quijano desenvolve um conceito que é amplamente usado pelos autores latino americanos, a colonialidade de poder (BALLESTRIN, 2013, p. 100). Esse conceito exprime que as relações de colonialidade nas esferas econômica 
e política não se esgotaram com a destruição do colonialismo. Com isso, Quijano procura denunciar "a continuidade das formas coloniais de dominação após o fim das administrações coloniais, produzidas pelas culturas coloniais e pelas estruturas do sistema-mundo capitalista moderno/colonial” e "atualizar e contemporizar processos que supostamente teriam sido apagados, assimilados ou superados pela modernidade” (BALLESTRIN, 2013, p. 100).

Esse conceito mostra como se dá a estruturação do sistema-mundo moderno/colonial que articula os lugares periféricos da divisão internacional do trabalho com a hierarquia étnico-racial global e com a inscrição de migrantes do Terceiro Mundo na hierarquia racial das cidades globais. Os Estados-Nação periféricos e os povos não-europeus vivem hoje sob o regime da “colonialidade global” imposto pelos Estados Unidos, através do Fundo Monetário Internacional, do Banco Mundial, do Pentágono e da OTAN (GROSFOGUEL, 2008, p. 126 apud BALLESTRIN, 2013, p. 100). Ainda que não estejam sobre uma administração colonial, as zonas periféricas do mundo ainda se mantém numa situação colonial. A colonialidade se reproduz em uma tripla dimensão: a do poder, do saber e do ser e, mais do que isso, "a colonialidade é o lado obscuro e necessário da modernidade; é a sua parte indissociavelmente constitutiva” (MIGNOLO, 2003, p. 30 apud BALLESTRIN, 2013, p. 100).

Para Quijano, raça, gênero e trabalho foram as três linhas principais de classificação que constituíram a formação do capitalismo mundial colonial/ moderno no século XVI. É nessas três instâncias que as relações de exploração/dominação/conflito estão ordenadas. O racismo é considerado como "o princípio organizador que estrutura todas as múltiplas hierarquias do sistema-mundo" (MIGNOLO, 2003, p. 30 apud BALLESTRIN, 2013, p. 101). Se a raça é uma categoria mental da modernidade, tem-se que seu sentido moderno não tem história conhecida antes da América. Para Mignolo, "pensar a conceitualização da colonialidade como constitutiva da modernidade é já colocar o pensamento de-colonial em marcha” (MIGNOLO, 2008, p. 249 apud BALLESTRIN, 2013, p. 105). Assim, podemos entender o pensamento decolonial ou giro decolonial como um movimento de resistência teórico e prática, política e epistemológica, à lógica da modernidade/colonialidade (MIGNOLO, 2008, p. 249 apud BALLESTRIN, 2013, p. 105). Segundo o autor, as origens da ideia de decolonialidade estavam já contidas em Quijano e Dussel de forma conjunta. O primeiro, desde seu artigo no qual desenvolve a ideia de colonialidade do poder, é claro quanto à necessidade de descolonização; o segundo, por sua vez, trouxe a noção de transmodernidade: a modernidade que nasce em 1492, com o “descobrimento”. Sua real superação se dá pela subsunção de seu caráter emancipador racional europeu transcendido como projeto 
mundial de libertação de sua Alteridade negada: a trans-modernidade (nos campos políticos, econômicos, ecológicos, religiosos) (MIGNOLO, 2008, p. 249 apud BALLESTRIN, 2013, p. 107). A trans-modernidade de Dussel propicia a pluralidade como projeto universal.

Cabe ainda dizer que embora se assuma a influência do pós-colonialismo, como vimos, o Grupo Modernidade/Colonialidade recusa a filiação a essa corrente. O mesmo se aplica às outras influências recebidas que possibilitaram o surgimento e o desenvolvimento da construção teórica do grupo. A teoria pós-colonial tem uma relação maior com o pósestruturalismo europeu (Foucault, Lacan e Derrida) e as experiências intelectuais nas excolônias inglesas da Ásia e África do Norte (MIGNOLO, 2008, p. 249 apud BALLESTRIN, 2013, p. 108). Assim, a decolonização se afasta do mainstream do pós-colonialismo, envolvendo diversas dimensões relacionadas com a colonialidade do ser, saber e poder, desde a América Latina.

\section{Críticas feministas ao debate decolonial}

Sem a pretensão de esgotar a riqueza da argumentação, apresentarei algumas contribuições do pensamento feminista latino americano de Breny Mendonza e Maria Lugones, para o pensamento decolonial latino americano, a partir da análise por elas realizada das teorias de A. Quijano e E. Dussel. Nota-se que a baixa participação das mulheres no grupo de Modernidade/Colonialidade, contradiz a tese de diálogo aberto e constante com o feminismo latino americano e pode ser a causa do problema, por elas diagnosticado, que impõe dificuldades para pensar a condição das mulheres, a partir dessas teorias.

\section{Colonialidade de gênero x Colonialidade de poder}

Segundo Quijano, como já dissemos, a ideia de raça é considerada “o princípio organizador que estrutura todas as múltiplas hierarquias do sistema-mundo”. Ela surge com a ideia de "descobrimento" e serve para reclassificar socialmente e de forma estratificada as pessoas das colônias segundo sua relação com cristianismo, a pureza de sangue e as línguas europeias. Assim, a ideia de raça reordena todas as áreas básicas da existência humana, que engloba todas as lutas de poder pelo controle dos recursos e dos produtos que delas derivam: sexo, trabalho, autoridade coletiva e subjetividade e intersubjetividade. A partir desta perspectiva, a ideia de raça reordena regimes de gênero preexistentes nas sociedades colonizadas e antes de sua colonização. O gênero é, portanto, subordinado à lógica de raça, talvez como antes o gênero foi subordinado à categoria de classe. Lugones reconhece o poder desse conceito e daí deriva seu conceito de 'colonialidade de gênero'. No entanto, baseia-se 
em uma crítica construtiva dos preconceitos de gênero que ela considera implícita na definição de Quijano da colonialidade do poder. Segundo Lugones, na narrativa lógica do conceito de colonialidade do poder, Quijano comete o erro de supor que o gênero, e até mesmo a sexualidade, são necessariamente elementos estruturantes de todas as sociedades humanas. Supondo aprioristicamente que seja assim, Quijano parece não ter consciência dos pressupostos patriarcais, heterossexistas e eurocêntricos que existem sobre o gênero. Lugones utiliza o trabalho de Oyuronke Oyewumi, feminista nigeriana e Paula Allen Gunn, feminista indígena norte-americana, para mostrar como o gênero, junto com a ideia de raça foram, ao mesmo tempo, construções coloniais para "racializar" e "generizar" as sociedades subordinadas. De acordo com essas feministas indígenas e africanas não existia, nas sociedades Yoruba ou povos indígenas da América do Norte (LUGONES apud MENDONZA, 2016, p. 22), o gênero tal como entendido no ocidente antes do "contato" com a organização colonizadora. Esses grupos não dividiam ou hierarquizavam suas sociedades com base em gênero e as mulheres tiveram igual acesso ao poder público e simbólico. Seus idiomas e sistemas de relações não continham uma estrutura que apontasse para uma subordinação de mulheres a homens. Não houve divisão sexual de trabalho e suas relações econômicas foram baseadas em princípios de reciprocidade e complementaridade. Por outro lado, a experiência baseada na idade cronológica foi o princípio organizador mais importante. Em suma, o sexual anatômico biológico teve pouco a ver com a organização social. Nessas sociedades também era comum a homossexualidade e reconheciam mais de dois "gêneros", contrariando o binarismo típico do Ocidente. Considerar que o gênero é um conceito anterior à sociedade e à história, como Quijano, tem o efeito de naturalizar as relações de gênero e a heterossexualidade, e pior ainda - diz Lugones - serve para encobrir o modo como as mulheres do terceiro mundo experimentaram a colonização e continuam a sofrer seus efeitos na pós-colonialidade (LUGONES apud MENDONZA, 2016, p. 23).

Disso conclui-se que nos processos de colonização, essas mulheres no mundo colonizado não eram apenas racializadas, mas também reinventadas como "mulheres" de acordo com os códigos e princípios discriminatórios de gênero, tal como entendido no Ocidente. A colonização criou as circunstâncias históricas para que as mulheres africanas e indígenas da América do Norte perdessem as relações relativamente igualitárias que tinham com os homens de suas sociedades e caíssem não apenas sob o domínio de homens colonizadores, mas também sob o domínio de homens colonizados (MENDONZA, 2016, p. 26). A subordinação de gênero era o preço que os homens colonizados negociavam para manter algum controle sobre suas sociedades. É essa negociação de homens colonizados com 
homens colonizadores que explica, segundo Lugones, a indiferença dos homens, incluindo os da esquerda política, em relação ao sofrimento das mulheres e seu silêncio em relação à violência enfrentada por elas. Esse conluio de homens colonizados com seus colonizadores é o que impede a construção de fortes laços de solidariedade entre mulheres e homens no terceiro mundo nos processos de libertação. Mas as consequências de ignorar a relação de colonialidade e gênero também afetam as mulheres brancas ocidentais. Disso resulta a dificuldade no movimento feminista contemporâneo de fazer as feministas brancas construírem sólidas alianças com feministas não brancas em países de terceiro mundo.

Outro ponto a ser considerado, é que o autor está ciente de que o trabalho assalariado foi reservado apenas para homens brancos, mas não se aprofunda nesse fato. Se assim o fizesse, segundo Mendonza, ele seria forçado a reconhecer que dentro da definição de trabalho assalariado há também uma conotação de gênero e não apenas racial. Se por um lado, sem a escravização dos africanos e da servidão indígena, não haveria capitalismo, por outro, deve ser levado em conta que a generalização do trabalho assalariado "livre" em primeiro lugar deve ter passado pela domesticação de mulheres na metrópole e, em seguida, por submetê-las a um regime de gênero nas colônias. Na Europa vimos como isso foi feito sistematicamente pela caça às bruxas desde o século XV por ambos os protestantes e pela Santa Inquisição Católica (MENDONZA, 2016, p. 27). Mais tarde, veríamos isso no que Marx chamou de processo de acumulação primitiva que desapossou as massas camponesas e separou em grande parte as mulheres da esfera produtiva, ao mesmo tempo em que as transformavam em donas de casa ou trabalhadores explorados (MENDONZA, 2016, p. 28). Nas colônias, vimos isso com os violentos massacres de mulheres indígenas como instrumento de guerra de conquista e colonização, a perda de seu status social e política, escravidão, redução à servidão e a intensidade letal do trabalho, entre outras coisas. Essa "domesticação" continua com os femicídios, o tráfico de mulheres pobres, o turismo sexual, a feminização da indústria e a pobreza sob o capitalismo neoliberal. Lugones e Mendonza concordam que a imposição das categorias de raça e gênero produziu rachaduras profundas nas possíveis solidariedades entre as mulheres na metrópole e periferia, e entre homens e mulheres da periferia.

O trabalho assalariado instituído com base na raça criou a base para um pacto social entre os capitalistas e a classe trabalhadora masculina de origem europeia (branca) em detrimento dos trabalhadores não assalariados não brancos. Tratava-se de um pacto social entre homens, de gênero, que teve implicações políticas na conformação da cidadania e não apenas econômica na construção de classe (MENDONZA, 2016, p. 28). Ora, a definição do 
trabalho assalariado como um privilégio dos homens brancos europeus impedia que a maioria dos homens brancos pobres caísse na escravidão e, ao mesmo tempo, os libertava do trabalho doméstico. Assim, enquanto o trabalho assalariado masculino foi sujeito à exploração capitalista, o pacto serviu para lançar as bases para a figura do cidadão do sexo masculino: um indivíduo livre que tem direitos, controle sobre seu corpo e o tempo de participação política; direitos legais, civis, individuais e políticos que excluem mulheres e escravos. Ou seja, sem o pano de fundo da escravidão nas colônias, não haveria tal cidadão e chefe de família masculino branco no Ocidente. Para resumir, a fusão da ideia de raça e a ideia de gênero são fundamentais para moldar a cidadania livre que o Ocidente conheceu quando o capitalismo e a democracia liberal foram interligados. Disso poderíamos concluir que a verdadeira democracia liberal existente no Ocidente só era possível por causa dessa fusão de raça e gênero (MENDONZA, 2016, p. 28).

É importante enfatizar que o pacto social de gênero entre homens brancos constituiu uma comunidade de interesses que excluía as mulheres brancas. Elas não tiveram o mesmo acesso à cidadania ou ao trabalho assalariado. As mulheres brancas perderam o controle sobre seus corpos e não se beneficiaram da colonialidade do poder da mesma maneira que os homens. Nesse sentido, elas tiveram que lutar pelo acesso ao trabalho assalariado que usufruem até hoje. Isso nos diz que o pacto de gênero entre os homens brancos realmente se baseia em uma base perversa. Por um lado, depende das relações de exploração capitalistas entre os homens e, por outro lado, requer a subordinação das mulheres. Contudo, as contradições internas das democracias capitalistas acabaram beneficiando as mulheres brancas da metrópole, que pouco a pouco conseguiram elevar-se a condição econômica e política dos homens brancos, com a condição de que aceitassem os termos racistas do pacto. Em síntese, a colonialidade do poder e a colonialidade de gênero operam internamente na América Latina e como diz Quijano, a independência dos países não significa uma descolonização das sociedades. Como os teóricos latino-americanos pensariam a dissolução desse pacto?

\section{O Gênero na perspectiva de Dussel}

Mendonza observa que Dussel se preocupa em lançar as bases para uma civilização transmoderna, transcapitalista, além do liberalismo e do socialismo. De acordo com seu modelo político proposto, podemos chegar a este momento histórico em que os excluídos do sistema neoliberal capitalista irrompem a história em lugares como o Fórum Social Mundial, movimento dos zapatistas ou das novas assembléias constituintes. Nesse conglomerado de movimentos que tomam o palco político pela primeira vez, as feministas são levadas em conta 
por sua exigência particular de respeito pelos direitos das mulheres. A incorporação de demandas feministas refletiria o slogan zapatista que Dussel retoma em seu plano político e que exige um mundo onde todos nos encaixamos, o mundo menos excludente possível. Dussel interpreta essa enunciação zapatista como uma fundação política que nos ajudaria a criar uma categoria unificadora de todos os movimentos, classes, raças, feminismos etc. A diversidade e as demandas particulares devem ser negociadas em torno de um bloco hegemônico. Este bloco hegemônico é o que ele chama de "povo", a comunidade, ou nossas tradições indígenas da América Latina, que difere do senso de comunidade totalizante do Ocidente, em que as diferenças são eliminadas.

Uma primeira crítica feminista à filosofia de Dussel foi feita por Viola acerca do conceito que é usado em teologia da libertação e está intimamente relacionado com o conceito de pessoas utilizado, opera como um conceito hegemônico indiferenciado que não inclui os sofrimentos das mulheres (MENDONZA, 2016, p. 30). Isto é, Viola identificou que os teólogos da libertação que reconhecem bem o sofrimento das mulheres aceitam a doutrina do Vaticano sem questionar quando se trata dos direitos reprodutivos delas. Não parece que Dussel tenha prestado atenção a essa crítica feminista, e sua tentativa de ser mais inclusivo com o termo pessoas, ainda não consegue ignorar seu viés masculinista.

Mendonza considera “impressionante” que o seu tratado político mantenha a divisão público/privado. Dussel começa afirmando que o privado é o espaço intersubjetivo que protege os sujeitos de serem observados e atacados por outros membros de outros sistemas intersubjetivos. Enquanto o público é o espaço intersubjetivo onde os sujeitos atuam com base em papéis e expostos ao olhar de outros atores de outros sistemas intersubjetivos. Estabelece que o público é o político por definição e que o público político é o único espaço onde a mudança civilizacional é possível. De uma perspectiva feminista, conservar essa divisão significa um movimento retrógrado no pensamento político.

O antigo slogan “o pessoal é político” é a base por excelência do feminismo. É problemático para as mulheres despolitizar e definir o privado como livre de conflitos de poder ou campo "pré-político", porque, como sabemos, as mulheres não são protegidas de serem atacadas pelos sistemas patriarcais intersubjetivos nos campos do privado. Partir de uma separação do privado e público para as feministas conservaria não só a colonialidade do gênero, mas também a concepção liberal eurocentrada de política que Dussel diz que quer terminar pois na medida em que este autor considera que a exclusão das mulheres e as demandas feministas só podem ser resolvidas publicamente, os conflitos da vida cotidiana e a microfísica do poder no setor privado são deixados para trás (MENDONZA, 2016, p. 32). O 
campo em que uma grande parte das violações dos direitos das mulheres ocorre é representado como parte do pré-político. Sua definição de política, para Mendonza, não dá conta da situação das mulheres.

Outro ponto a ser analisado por Mendonza é a ideia de Dussel de que a nova política tem como objetivo a perpetuação da vida. Esta nova política dá prioridade ao desejo de permanecer vivo perante o desejo de matar. O novo paradigma político negaria a necropolítica da razão genocida ocidental que justifica a morte de mais de dois terços da humanidade e de seus recursos, e promoveria existência contínua à vida dos outros: os excluídos. Achille Mbembe (2018) formula o conceito de necropolítica para descrever os mecanismos pelos quais se estabelece e se mantém controle sobre quem pode viver e quem deve morrer. Todos os estados modernos classificam as vidas de seus súditos em um sistema onde a morte de certos corpos não é apenas esperada, mas é até mesmo lucrativa.

Isso equivale a sobreviver prosperando com o outro: os excluídos, os pobres, o povo. É uma política, como Dussel a chama, de "alteridade". O ethos da política da alteridade é a própria vida, a vida concreta de cada pessoa é o começo e o fim. A vocação política deve ser destinada a satisfazer as necessidades vitais das pessoas, nas quais o poder reside. A função das instituições políticas é cumprir este mandato do povo. Nutrindo novamente os zapatistas, a prática política baseia-se em mandar obedecer, ouvir aqueles que nos precedem. E não em uma renúncia e alienação do poder de sua fonte, o povo.

O ponto de partida da política da alteridade não pode ser o indivíduo isolado como Robinson Crusoé foi. Dussel exclama que Robinson não poderia mesmo ter nascido sem a comunidade, mas sem uma mulher tão pouco, acrescentam Mendonza, revelando mais uma vez a turvação das relações de gênero nos conceitos unitários de comunidade e aldeia. O paradoxo é que Dussel não reconhece o princípio feminino e mesmo feminista presente em seu discurso. O novo paradigma político que ele propõe tem certa semelhança com o pensamento materno de Sarah Ruddick e a construção de uma política de paz e não-violência.

O trabalho materno nesse sentido - assim como a política da alteridade - tem como princípio fundamental a conservação da vida; Trata-se também da criação de uma vida em que os seres humanos crescem e prosperam livres da violência e desenvolvem uma intersubjetividade tanto no privado quanto no público, baseada na reciprocidade e na não violência. Poderíamos dizer que o pensamento feminista vai além de Dussel, porque é profundamente anti-militarista e não justifica a violência sob nenhuma circunstância. Dussel, por outro lado, conserva o direito de usar a violência em caso de autodefesa da comunidade, embora não diga quando se chega à situação em que a violência é justificada. 
Em última análise, para ambas as autoras, se o pensamento pós-ocidentalista há de levar a sério a inclusão das vozes das mulheres, também precisa estabelecer um diálogo com as feministas latino-americanas. As feministas latino-americanas, por sua vez, têm o dever de desenvolver um pensamento decolonial que articule e revele como a colonialidade de gênero, raça, classe e sexualidade continuam a contaminar as nossas sociedades e nosso pensamento e nossas relações.

\section{Conclusão}

As filosofias de Dussel e Quijano, bem como de outros autores decoloniais, trouxeram ferramentais teóricos excelentes para se pensar a condição dos subalternos no mundo. Contudo, submetidas a um escrutínio feminista, elas ainda revelam traços de um pensamento masculinista, que se mostra incapaz de abranger adequadamente a experiência das mulheres. Além disso, revela limitações quanto à compreensão do lugar que o gênero ocupa como objeto nesse programa de investigação. Talvez seja preciso reconhecer que mesmo os intelectuais decoloniais latino-americanos não consigam pôr em prática o que propõem e, para isso, precisassem se servir mais intensamente de práticas que visem efetivamente traduzir a voz do Outro. Isso pode ser realizável, na medida que se crie um diálogo mais aberto com as feministas latino-americanas, não somente com uma parte delas. Outra questão que se coloca é a falta de autoras referenciadas em suas obras. Em que medida esses autores consideram importante a participação de mulheres latino-americanas no contexto da produção intelectual e ativismo político? A solução dos problemas traduzidos por Lugones e Mendonza, passa por um redesenho das categorias gênero e patriarcado, mulher e feminismo, nos debates centrais da luta política decolonial, recolocando termos e possibilitando discutir como garantir às mulheres, nessas condições, a democracia, a igualdade de representações, a justiça e a cidadania integral. 


\section{Referências Bibliográficas}

BALLESTRINI, L. América Latina e o giro decolonial. Revista Brasileira de Ciência Política, n. 11, p. 89-117, 2013.

DUSSEL, E. La Filosofía de la Liberación ante los estudios poscoloniales y subalternos y la Posmodernidad. Filosofías del Sur. Descolonización y Transmodernidad. Ediciones Akal: México, 2015.

MENDONZA, B. La epistemologia del sur, la colonialidad del género y el feminismo latinoamericano. Estudios descoloniales, 13 de Agosto, 2016.

QUIJANO, A. Colonialidade do poder, eurocentrismo e América Latina. In: A colonialidade do saber, Eurocentrismo e ciências sociais. Perspectivas Latinoamericanas. Buenos Aires: GLACSO, 2005. 